\title{
Implementasi Program Kota Tanpa Kumuh (KOTAKU) Di Kelurahan Purbalingga Kidul Kecamatan Purbalingga Kabupaten Purbalingga
}

\author{
${ }^{1}$ Laras Saketi, ${ }^{2}$ Ngalimun, ${ }^{3}$ Denok Kurniasih \\ Program Studi Ilmu Administrasi Negara Fakultas Ilmu Sosial dan Ilmu \\ Politik Universitas Jenderal Soedirman
}

\begin{abstract}
Policy implementation is the implementation of a policy so that the objectives of the policy can be achieved. Implementation in terms of reducing slum area is one of the problems in Indonesia. The problem in this study was motivated by the lack of fulfillment of clean water needs, the people who participated less in the implementation of the KOTAKU program, and the absence of policies that supported the KOTAKU Program in the Purbalingga Kidul Village. This study aims to determine how much influence the idealized policy, target group, implementing organization and environmental factors have on the successful implementation of the No Slum City Program (KOTAKU) in the Purbalingga Kidul Village. The research method used was quantitative associative with a sample of 116 respondents and the sampling technique used the census method or total sampling. The analytical method used is Kendall Tau-c Correlation, Kendall $W$ Concordance Coefficient and Ordinal Regression Analysis. The results of the study show that: (1) There is a positive and significant influence between the idealized policy on the success of the implementation and the regression coefficient of 0.608. (2) There is a positive and significant influence between the target group on the success of the implementation with a regression coefficient of 0.413. (3) There is a positive and significant influence between implementing organization on the success of implementation with a regression coefficient of 0.645. (4) There is a positive and significant influence between the environmental factors on the success of the implementation with a regression coefficient of 0.706. (5) There is a positive and significant influence between idealized policy, target group, implementing organization and environmental factors on the success of implementation with a regression coefficient of 0.824 .
\end{abstract}

Keywords: Successful Implementation, Idealized Policy, Target Group, Implementing Organization, Environmental Factor

\begin{abstract}
Abstrak
Implementasi kebijakan adalah pelaksanaan suatu kebijakan agar tujuan dari kebijakan tersebut bisa tercapai. Implementasi dalam hal pengurangan luasan kumuh merupakan salah satu masalah yang ada di Indonesia. Permasalahan dalam penelitian ini dilatarbelakangi oleh belum terpenuhinya kebutuhan air bersih, masyarakat yang kurang berpartisipasi dalam pelaksanaan program KOTAKU, dan belum adanya kebijakan yang mendukung Program KOTAKU di Kelurahan Purbalingga Kidul. Penelitian ini bertujuan untuk mengetahui seberapa besar pengaruh idealized policy, target group, implementing organization dan environmental factor terhadap keberhasilan implementasi Program Kota Tanpa Kumuh (KOTAKU) di Kelurahan Purbalingga Kidul. Metode penelitian yang digunakan adalah kuantitatif asosiatif dengan sampel 116 responden dan teknik pengambilan sampel menggunakan metode sensus atau sampling total. Metode analisis yang digunakan adalah Korelasi Kendall Tau-c, Koefisien Konkordansi Kendall W dan Analisis Regresi Ordinal. Hasil Penelitian menunjukkan bahwa: (1) Terdapat pengaruh yang positif dan signifikan antara idealized policy terhadap keberhasilan implementasi dengan nilai koefisien regresi sebesar 0,608. (2) Terdapat pengaruh yang positif dan
\end{abstract}


signifikan antara target group terhadap keberhasilan implementasi dengan nilai koefisien regresi sebesar 0,413. (3) Terdapat pengaruh yang positif dan signifikan antara implementing organization terhadap keberhasilan implementasi dengan nilai koefisien regresi sebesar 0,645. (4) Terdapat pengaruh yang positif dan signifikan antara environmental factor terhadap keberhasilan implementasi dengan nilai koefisien regresi sebesar 0,706. (5) Terdapat pengaruh yang positif dan signifikan antara idealized policy, target group, implementing organization dan environmental factor terhadap keberhasilan implementasi dengan nilai koefisien regresi sebesar 0,824.

Kata Kunci: Keberhasilan implementasi, Kebijakan yang Ideal, KelompokSasaran, Badan Pelaksana, Faktor Lingkungan

*)Penulis Korespondensi

E-mail : denokkurniasih@yahoo.com 


\section{PENDAHULUAN}

Implementasi

kebijakan

merupakan tahap yang paling penting dalam proses kebijakan publik, karena suatu kebijakan harus diimplementasikan agar kebijakan tersebut mempunyai dampak dan sesuai dengan tujuan yang diharapkan. Menurut Budi Winarno (2012: 102) proses implementasi kebijakan publik baru dapat dimulai apabila tujuan-tujuan kebijakan publik telah ditetapkan, program-program telah dibuat dan dana telah dialokasikan untuk pencapaian tujuan kebijakan tersebut. Salah satu masalah implementasi kebijakan yang ada di Indonesia contohnya adalah implementasi dalam hal pengurangan luasan kumuh.

Untuk meningkatkan kualitas permukiman kumuh, mencegah tumbuhnya permukiman kumuh baru dan penghidupan yang berkelanjutan maka Direktorat Jenderal Cipta Karya mengenalkan pembangunan platform Purbalingga Lor seluas 4,85 Ha dan satu kelurahan yang masuk kategori lingkungan kumuh sedang yaitu Purbalingga Kidul seluas 2,22 Ha. Kelurahan Purbalingga Kidul merupakan permukiman padat yang tidak difasilitasi sarana prasarana yang memadai sehingga Kelurahan Purbalingga Kidul masuk kategori lingkungan kumuh sedang dan memiliki tingkat kekumuhan yang lebih kompleks daripada kelurahan lainnya. kolaborasi melalui Program Kota Tanpa Kumuh (Kotaku). Kriteria perumahan dan permukima kumuh tercantum pada Pasal 4 ayat (2) Permen PUPR No. 02/PRT/M/2016 yang meliputi tujuh indikator yaitu: (1) bangunan gedung; (2) jalan lingkungan; (3) penyediaan air minum; (4) drainase; (5) pengelolaan air limbah; (6) pengelolaan persampahan dan (7) proteksi kebakaran. Kabupaten Purbalingga merupakan salah satu kabupaten yang menjadi target RPJMN 2015-2019 tentang kota tanpa permukiman kumuh pada tahun 2019. Berdasarkan SK Bupati No. 643/351 Tahun 2014 terdapat 5 (lima) kelurahan yang mendapatkan SK Kumuh Bupati dengan total luasan kumuh 32,39 Ha. Ada empat kelurahan yang masuk kategori lingkungan kumuh ringan yaitu Kandanggampang seluas 10,78 $\mathrm{Ha}$, Purbalingga Wetan seluas 8,15 $\mathrm{Ha}$, Kembaran Kulon seluas 6,39 $\mathrm{Ha}$,

Pelaksanaan Program Kotaku sudah dimulai sejak tahun 2016 melalui tahap sosialisasi dan dilanjutkan dengan pelaksanaan pengurangan kawasan kumuh berdasarkan tujuh indikator kumuh. Implementasi Program Kotaku di Kelurahan Purbalingga sudah berjalan walaupun masih terdapat masalah-masalah yang membuat implementasi program tersebut belum bisa berjalan dengan maksimal. Permasalahan pertama, yaitu idealized policy merupakan kebijakan yang ideal bagi 
masyarakat, namun masih ada masyarakat yang menganggap kebijakan pada Program Kotaku kurang ideal, hal ini terbukti dari adanya beberapa masyarakat yang kurang mampu bekerjasama dalam penataan kondisi bangunan serta masih ada masyarakat yang belum terpenuhi kebutuhan air bersih dan minum. Permasalahan kedua, yaitu kelompok sasaran dalam Program Kotaku di Kelurahan Purbalingga Kidul belum siap menerima program, hal ini terbukti dari sudah tersedianya sarana proteksi kebakaran namun pada saat simulasi kebakaran masyarakat belum mampu mengaplikasikan sarana proteksi kebakaran tersebut, hal ini mengakibatkan terjadinya kebakaran di lokasi simulasi. Permasalahan ketiga, yaitu belum adanya kebijakan yang mendukung Program KOTAKU di Kelurahan Purbalingga Kidul. Hal ini menyebabkan masih adanya masyarakat yang membuang sampah sembarangan, menjemur pakaian di depan rumah dan dipinggiran sungai yang menyebabkan lingkungan menjadi tidak rapi dan terlihat kumuh. Hal-hal tersebut merupakan permasalahan dalam implementasi Program Kotaku di Kelurahan Purbalingga Kidul.

Menurut Thomas B. Smith (dalam Fadillah Putra, 2001:90) implementasi kebijakan dipandang sebagai suatu proses atau alur. Model ini memandang proses implementasi kebijakan dari perspektif perubahan sosial dan politik, dimana kebijakan yang dibuat oleh pemerintah bertujuan untuk mengadakan perbaikan atau perubahan dalam masyarakat sebagai kelompok sasaran. Keberhasilan atau kegagalan suatu implementasi kebijakan tidak terlepas dari faktor-faktor yang mempengaruhi implementasi kebijakan tersebut. Model implementasi kebijakan menurut Thomas B. Smith dianggap tepat untuk membantu menjelaskan permasalahan dalam pelaksanaan Program Kota Tanpa Kumuh (Kotaku) di Kelurahan Purbalingga Kidul Kecamatan Purbalingga kabupaten Purbalingga. Menurut Thomas B. Smith ada empat variabel yang mempengaruhi keberhasilan implementasi kebijakan, antara lain yaitu idealized policy, target group, implementing organization dan environmental factor. Keempat variabel tersebut bersinergi satu sama lain dan saling mempengaruhi dalam pencapaian tujuan kebijakan.

Berdasarkan latar belakang masalah, rumusan masalah dalam penelitian ini adalah adakah pengaruh yang positif dan signifikan antara idealized policy (X1), target group (X2), implementing organization (X3) dan environmental factor (X4) terhadap keberhasilan implementasi Program Kotaku di Kelurahan Purbalingga Kidul (Y). Untuk menjawab rumusan masalah dan membuktikan hipotesis digunakan uji regresi ordinal, yaitu analisis regresi yang digunakan bila data yang dimasukkan memiliki variabel dengan skala pengukuran ordinal minimal ordinal. Tujuan dari penelitian ini adalah untuk 
mengetahui dan menguji pengaruh idealized policy, target group, implementing organization dan environmental factor terhadap keberhasilan implementasi Program Kotaku di Kelurahan Purbalingga Kidul Kecamatan Purbalingga Kabupaten Purbalingga baik secara mandiri maupun secara bersamasama.

Penelitian yang mengkaji
tentang implementasi kebijakan sudah banyak dilakukan, diantaranya dilakukan oleh Tauhid (2017), Indah Pratiwi, dkk (2014), Aji Ratna Kusuma, dkk (2018), Asna Aneta (2010), Sri Wahyuni, dkk (2012), Sri Maryuni, dkk (2015), Ombi Romli (2017), Dimas Alif Budi N, dkk (2013). Ilham Arief Sirajuddin (2014) dan Sri Yuliani, dkk (2017). Pada penelitian Tauhid (2017) berjudul Implementasi Kebijakan Revitalisasi Kota Tanpa Kumuh Neigborhood Upgrading and Shelter Sector Project (NUSSP) di Kota Bima, hasil penelitian tersebut yaitu implementasi kebijakan revitalisasi kota tanpa kumuh telah dilaksanakan dengan tingkat pencapaian 100\% sesuai dengan Program Kotaku di masing-masing kelurahan dan di Kota Bima, Program Kotaku lebih difokuskan pada perbaikan infrastruktur dan penataan drainase, gang, jalan lingkungan, pembangunan dan perbaikan sanitasi lingkungan dan kebutuhan untuk air bersih masyarakat. Penelitian Sri Wahyuni, dkk (2012) berjudul Implementasi Kebijakan Pembangunan dan Penataan Sanitasi Lingkungan Berbasis Masyarakat
(SLBM) di Kabupaten Tulungangung, hasil dari penelitian ini menunjukkan bahwa Program SLBM di Kabupaten Tulungangung secara umum belum optimal pelaksanaannya karena ditemukan kelemahan dari sisi penentuan lokasi pelaksanaan RPA, operasional dan pemeliharaan yang kurang. Penelitian Ombi Romli (2017) berjudul Implementasi Program Beras Miskin (Raskin) di Desa Saketi Kecamatan Saketi Kabupaten Pandeglang, hasil penelitian ini menunjukkan bahwa implementasi program raskin di Desa Saketi tidak tepat sasaran, hal ini terjadi karena Kepala Keluarga (KK) yang tidak tercatat dalam daftar Rumah Tangga Sasaran (RTS) juga menerima Raskin, dan jumlah beras yang diterima oleh RTS tidak sesuai dengan yang seharusnya.

Perbedaan penelitian ini dengan penelitian terdahulu terletak pada lokus, fokus dan metode penelitiannya. Lokus penelitian ini dilakukan di Kelurahan Purbalingga Kidul Kecamatan Purbalingga Kabupaten Purbalingga dengan fokus untuk mengetahui adanya pengaruh antara idealized policy, target group, implementing organization dan environmental factor terhadap keberhasilan implementasi Program Kotaku di Kelurahan Purbalingga Kidul yang mengadopsi teori implementasi menurut Thomas B. Smith. Metode penelitian yang digunakan yaitu kuantitatif assosiatif.

\section{METODE PENELITIAN}

Metode yang digunakan dalam penelitian ini adalah metode 
kuantitatif asosiatif, dimana penelitian ini bertujuan untuk mengetahui hubungan antara dua variabel atau lebih (Sugiyono, 2011:11). Teknik pengambilan sampel dalam penelitian ini menggunakan metode sampling total atau sensus. Dalam penelitian ini yang dijadikan sampel adalah $116 \mathrm{KK}$ di RT 002 RW 001 Kelurahan Purbalingga Kidul sebagai penerima manfaat Program Kotaku. Teknik pengumpulan data dalam penelitian ini menggunakan kuesioner, observasi dan dokumentasi. Teknik analisis data yang digunakan adalah

\section{Hubungan Idealized Policy (X1) Terhadap Keberhasilan Implementasi (Y)}

Tabel 1. Uji Korelasi Kendall Tau-C variabel idealized policy (X1) dengan variabel keberhasilan implementasi $(\mathrm{Y})$

\begin{tabular}{|l|c|c|c|}
\hline Korelasi & Koefisien & Sig. Hitung & Keterangan \\
\hline T-c X1.Y & 0,512 & 0,000 & Signifikan \\
\hline
\end{tabular}

Sumber: Data primer diolah, 2019

Berdasarkan tabel 1 diketahui bahwa nilai korelasi antara variabel idealized policy (X1) dengan variabel keberhasilan implementasi $(\mathrm{Y})$ dapat diterima karena hasil analisis korelasi yang didapat adalah $r$ hitung $>\mathrm{r}$ tabel atau $0,512>0,1535$ dengan arah positif. Hal tersebut bermakna bahwa perubahan yang

\section{Hubungan Target Group (X2) Terhadap Keberhasilan Implementasi} (Y)

Tabel 2. Uji Korelasi Kendall Tau-C variabel target group (X2) dengan variabel keberhasilan implementasi $(\mathrm{Y})$

\begin{tabular}{|l|c|c|c|}
\hline Korelasi & Koefisien & Sig. Hitung & Keterangan \\
\hline T-c X2.Y & 0,358 & 0,000 & Signifikan \\
\hline
\end{tabular}


Sumber: Data primer diolah, 2019

Berdasarkan tabel 2 diketahui bahwa nilai korelasi antara variabel target group (X2) dengan variabel keberhasilan implementasi (Y) dapat diterima karena hasil analisis korelasi yang didapat adalah $r$ hitung $>r$ tabel atau 0,358 $>0,1535$ dengan arah positif. Hal tersebut bermakna bahwa perubahan yang dialami variabel target group (X2) akan diikuti secara positif oleh variabel keberhasilan implementasi $(\mathrm{Y})$, dengan kata lain semakin tinggi target group akan semakin tinggi pula keberhasilan implementasi.

\section{Hubungan Implementing Organization (X3) Terhadap Keberhasilan}

\section{Implementasi (Y)}

Tabel 3. Uji Korelasi Kendall Tau-C variabel implementing organization

(X3) dengan variabel keberhasilan implementasi

(Y)

\begin{tabular}{|l|c|c|c|}
\hline Korelasi & Koefisien & Sig. Hitung & Keterangan \\
\hline T-c X3.Y & 0,418 & 0,000 & Signifikan \\
\hline
\end{tabular}

Sumber: Data primer diolah, 2019

Berdasarkan tabel 3 diketahui bahwa nilai korelasi antara variabel implementing organization (X3) dengan variabel keberhasilan implementasi (Y) dapat diterima karena hasil analisis korelasi yang didapat adalah $\mathrm{r}$ hitung $>\mathrm{r}$ tabel atau 0,418>0,1535 dengan arah positif. Hal tersebut bermakna bahwa perubahan yang dialami variabel implementing organization (X3) akan diikuti secara positif oleh variabel keberhasilan implementasi (Y), dengan kata lain semakin tinggi implementing organization akan semakin tinggi pula keberhasilan implementasi.

\section{Hubungan Environmental Factor (X4) Terhadap Keberhasilan}

\section{Implementasi (Y)}

Tabel 4. Uji Korelasi Kendall Tau-C variabel environmental factor (X4) dengan variabel keberhasilan implementasi (Y) 


\begin{tabular}{|l|c|c|c|}
\hline Korelasi & Koefisien & Sig. Hitung & Keterangan \\
\hline T-c X4.Y & 0,465 & 0,000 & Signifikan \\
\hline
\end{tabular}

Sumber: Data primer diolah, 2019

Berdasarkan tabel 4 diketahui bahwa nilai korelasi antara variabel environmental factor (X4) dengan variabel keberhasilan implementasi (Y) dapat diterima karena hasil analisis korelasi yang didapat adalah $r$ hitung> $r$ tabel atau $0,465>$ 0,1535 dengan arah positif.
Kemudian diketahui pula bahwa nilai sig. hitung < taraf kesalahan atau $0,000<0,05$. Sehingga dapat dinyatakan terdapat hubungan yang positif dan signifikan antara variabel environmental factor (X4) dengan variabel keberhasilan implementasi (Y).

5. Hubungan Idealized Policy (X1), Target Group (X2), Implementing Organization (X3) dan Environmental Factor (X4) Terhadap Keberhasilan Implementasi (Y)

Tabel 5. Uji Korelasi Konkordansi Kendall W

\begin{tabular}{|c|c|c|c|c|c|}
\hline $\begin{array}{c}\text { Korelas } \\
\text { i } \\
\text { Unnl_nndan }\end{array}$ & $\begin{array}{c}\text { Koefisien } \\
\text { Korelasi }\end{array}$ & $\begin{array}{c}\text { Chi } \\
\text { Square }\end{array}$ & $\begin{array}{c}\text { Chi } \\
\text { Square }\end{array}$ & Df & $\begin{array}{c}\text { Asymp } \\
\text {.Sig }\end{array}$ \\
\hline X1.X2.X3.X4.Y & 0,345 & 159,973 & 9,487 & 4 & 0,000 \\
\hline
\end{tabular}

Sumber: Data primer diolah, 2019

Berdasarkan tabel 5 diketahui bahwa koefisien Kendall W sebesa 0,345 yang berarti variabel idealized policy (X1), target group (X2), implementing organization (X3), environmental factor (X4) dan keberhasilan implementasi (Y) memiliki hubungan simultan dengan arah yang positif. Artinya semakin tinggi idealized policy (X1), target group (X2), implementing organization (X3) dan environmental factor (X4), maka akan semakin tinggi pula keberhasilan implementasi (Y). Untuk mengetahui signifikansi yaitu dengan membandingkan Chi-square hitung dan Chi-square tabel, jika Chisquare hitung $>$ Chi-square tabel maka hubungan kedua variabel dikatakan signifikan. Hasil perhitungan diketahui Chi-square hitung>Chi-square tabel yaitu sebesar 159,973 > 9,487. Sehingga dapat dinyatakan terdapat hubungan secara bersama-sama yang positif dan signifikan antara variabel variabel idealized policy (X1), target group (X2), implementing organization (X3), environmental factor (X4) dan keberhasilan implementasi $(\mathrm{Y})$

Berdasarkan hasil analisis regresi ordinal antara idealized policy, target group, implementing organization dan environmental factor terhadap keberhasilan implementasi 
Program Kotaku di Kelurahan

Purbalingga Kidul menghasilkan koefisien sebesar 0,824 atau dengan kata lain pengaruh yang diberikan idealized policy, target group, implementing organization dan environmental factor terhadap keberhasilan implementasi Program Kotaku di Kelurahan Purbalingga Kidul sebesar 82,4 persen. Hasil penelitian ini dapat membuktikan teori Thomas B. Smith yang menyatakan bahwa faktor-faktor yang dapat mempengaruhi keberhasilan implementasi diantaranya yaitu idealized policy, target group, implementing organization dan environmental factor. Dimana faktor-faktor tersebut saling berhubungan dan saling mempengaruhi. Hasil penelitian ini menunjukkan bahwa untuk meningkatkan keberhasilan implementasi Program Kotaku di Kelurahan Purbalingga Kidul dapat dilakukan dengan memperbaiki idealized policy, target group, implementing organization dan environmental factor.

\section{KESIMPULAN}

Berdasarkan hasil penelitian dan pembahasan yang telah dipaparkan, maka dapat ditarik kesimpulan bahwa:

1. Varibel idealized policy (X1) terhadap keberhasilan implementasi (Y) memiliki nilai pengaruh sebesar 0,512 . Dengan demikian, hipotesis pertama yang menyatakan bahwa terdapat pengaruh yang positif dan signifikan antara idealized policy terhadap keberhasilan implementasi Program
Kotaku di Kelurahan Purbalingga Kidul diterima.

2. Varibel target group (X2) terhadap keberhasilan implementasi (Y) memiliki nilai pengaruh sebesar 0,358. Dengan demikian, hipotesis kedua yang menyatakan bahwa terdapat pengaruh yang positif dan signifikan antara target group terhadap keberhasilan implementasi Program Kotaku di Kelurahan Purbalingga Kidul diterima.

3. Varibel implementing organization (X3) terhadap keberhasilan implementasi (Y) memiliki nilai pengaruh sebesar 0,418. Dengan demikian, hipotesis ketiga yang menyatakan bahwa terdapat pengaruh yang positif dan signifikan antara implementing organization terhadap keberhasilan implementasi Program Kotaku di Kelurahan Purbalingga Kidul diterima.

4. Varibel environmental factor (X4) terhadap keberhasilan implementasi (Y) memiliki nilai pengaruh sebesar 0,465. Dengan demikian, hipotesis keempat yang menyatakan bahwa terdapat pengaruh yang positif dan signifikan antara environmental factor terhadap keberhasilan implementasi Program Kotaku di Kelurahan Purbalingga Kidul diterima.

5. Variabel idealized policy (X1), target group (X2), implementing organization (X3) dan environmental factor (X4)terhadap keberhasilan 
implementasi (Y) memiliki nilai pengaruh sebesar 0,345. Dengan demikian hipotesis ketiga yang menyatakan bahwa idealized policy, target group, implementing organization dan environmental factor secara bersama-sama mempunyai pengaruh yang positif dan signifikan terhadap keberhasilan implementasi Program Kotaku di Kelurahan Purbalingga Kidul Kecamatan Purbalingga Kabupaten Purbalingga.

\section{DAFTAR PUSTAKA}

Aji Ratna Kusuma, Santi Rande \& Sahria Aprilliana. (2018). Partisipasi Masyarakat dalam Pelaksanaan Program Kota Tanpa Kumuh (Kotaku) (Studi Tentang Program Pembangunan Drainase dan Sanitasi di Kelurahan Teritip Kota Balikpapan). eJurnal Administrasi Negara, Volume

6, Nomor 1: 7034-7048

Asna Aneta. (2010). Impelementasi Kebijakan Program

Penanggulangan

Kemiskinan Perkotaan (P2KP) di Kota Gorontalo. Jurnal Administrasi Publik, Volume 1, Nomor 1: 54-65
Dimas Alif Budi N., M. Saleh Soeaidy dan Minto Hadi. (2013). Implementasi Program Pemberdayaan Masyarakat Melalui Pelatihan Keterampilan Dasar (Studi di Kecamatan Tambaksari Kota Surabaya). Jurnal Administrasi Publik, Volume 1, Nomor 5:862871

Ilham Arief Sirajuddin. 2014. Implementasi Kebijakan Pemerintah Daerah dalam Pelayanan Publik Dasar Bidang Sosial di Kota Makassar. Jurnal Administrasi Publik, Volume 4, Nomor 1:1-14

Indah Pratiwi Wibawati, Soesilo Zauhar dan Riyanto. (2014). Implementasi Kebijakan Promosi Kesehatan Masyarakat Dinoyo Kecamatan Lowokwaru Kota Malang. Jurnal Administrasi Publik, Volume 2, Nomor 11:1-5

Ombi Romli. (2017). Implementasi Program Beras Miskin (Raskin) di Desa Saketi Kecamatan Saketi Kabupaten Pandeglang. Jurnal Kajian Administrasi dan Pemerintah Daerah, Volume 10, Nomor 6:8797

Sri Maryuni. (2015). Implementasi Program Nasional Pemberdayaan 
Masyarakat (PNPM)

Mandiri Perkotaan di

Kota Pontianak. Jurnal

Spirit Publik, Volume 10,

Nomor 1:19-30

Sri Yuliani dan Gusty Putri

Dhini Rosyida. (2017).

Kolaborasi Dalam

Perencanaan Program

Kota Tanpa Kumuh

(Kotaku) di Kelurahan

Semanggi Kota

Surakarta. Jurnal

Wacana Publik, Volume

1, Nomor 2:

$33-47$

Sri Wahyuni, Onny Setiani, Suharyanto. (2012).

Implementasi Kebijakan

Pembangunan dan

Penataan Sanitasi

Lingkungan Berbasis

Masyarakat di

Kabupaten

Tulungangung. Jurnal Ilmu Lingkungan,

Volume 10, Issue 2:

111-122

Sugiyono. 2011. Metode Penelitian Kuantitatif. Bandung: Alfabeta
Tauhid. (2017). Implementasi Kebijakan dan Revitalisasi Kota Tanpa Kumuh Neigborhood Upgrading and Shelter Sector Project (NUSSP) di Kota Bima. Jurnal Administrasi Negara, Volume 14, Nomor 3: 118-133

Winarno, Budi. 2002. Kebijakan dan Proses Kebijakan Publik. Yogyakarta: Media Pressindo

Radar Banyumas, 2016, Lima Kelurahan di Purbalingga masuk Kawasan

Kumuh,[online], (http://radarbanyumas. co.id/lima-kelurahan-dipurbalingga-masukkawasan kumuh/, diakses tanggal 5 November 2018 pukul 11.00) Peraturan Menteri PUPR PUPR No. 02/PRT/M/2016

Putra, Fadillah. 2001. Paradigma Kritis Dalam Studi Kebijakan Publik. Yogyakarta: Penerbit Pustaka Pelajar 